\title{
ANÁLISIS NORMATIVO Y JURISPRUDENCIAL ACERCA DE LOS INCREMENTOS PENSIONALES EN EL RÉGIMEN DE PRIMA MEDIA CON PRESTACIÓN DEFINIDA
}

\author{
REGULATORY AND ANALYSIS JURISPRUDENCE ABOUT THE PENSION \\ INCREASES IN THE SCHEME WITH DEFINED BENEFIT MEDIA PRIMA.
}

\author{
POLO POLO, Juan Carlos *
}

\section{RESUMEN}

La presente investigación se realiza con el fin de conocer la naturaleza de los incrementos pensionales creados para aquellos jubilados por vejez e invalidez por medio del Acuerdo $\mathrm{N}^{\circ} 224$ de 1966 emanado del Consejo Directivo del Instituto Colombiano de Seguros Sociales a través del cual se expidió el Reglamento General del Seguro Social Obligatorio de Invalidez, Vejez y Muerte. Una vez leído los resultados de la presente investigación, el lector tendrá claridad acerca de la vigencia o no de los mismos en el actual sistema pensional que rige a los colombianos y si en criterio de la Jurisprudencia emanada por las altas cortes jurisdiccionales de nuestro país, los mismos se encuentran o no sometidos al fenómeno jurídico de la prescripción.

PALABRAS CLAVES: Pensión, cónyuge, hijo, dependencia económica, convivencia

\begin{abstract}
This current scientific essay was done ir order to show some reasons of the increase of pension, which was done to retired people by old age and disability according to the Agreement Number 224 of 1966 given by NATIONAL COUNCIL OF SOCIAL AND OBLIGATORY SECURES, trough which it was issued The General Rule of Social and Obligatory Secure for Disability, Old Age and Death. After reading the results of the research, reader can know how this rule will take effect or not in the current system of pension, that rules Colombean people and furthermore how, base don the criterion of the jurisprudence oh High Courts, it is submitted or not in the juridical phenomenon of prescription.
\end{abstract}

Fecha de recibo: 16 de Septiembre de 2015

Fecha de aprobación: 27 de Noviembre de 2015

* Abogado titulado - egresado de la Facultad de Ciencias Jurídicas de la Universidad del Atlántico. vinculado laboralmente a la Rama Judicial del Poder Público a través del Juzgado $4^{\circ}$ Laboral del Circuito de Barranquilla.. juancarlos_0718@ hotmail.com 
KEY WORDS: Pension, spouse, child, economic dependence, coexistence.

\section{INTRODUCCIÓN}

El legislador colombiano a través de la Ley $\mathrm{N}^{\circ} 90$ de 1946 creó al Instituto de Seguros Sociales entre otros, con el fin de cubrir los riesgos de invalidez, vejez y muerte para aquellos trabajadores que entraren a efectuar cotizaciones al sistema pensional que dicha entidad administraría. Una vez creado el ente en mención, se expidió por parte del Consejo Directivo del Instituto Colombiano de Seguros Sociales a través del Acuerdo $\mathrm{N}^{\circ} 224$ de 1966 el Reglamento General del Seguro de Invalidez, Vejez y Muerte, Acuerdo que posteriormente fue aprobado por el Gobierno Nacional a través del Decreto $\mathrm{N}^{\circ}$ 3041 de 19 de Diciembre del mismo año y que en su artículo 16 consagró para los pensionados por invalidez y vejez de dicho régimen, el derecho al incremento de su mesada pensional en un catorce por ciento $(14 \%)$ sobre la pensión mínima por tener cónyuge a su cargo, y en un siete por ciento ( $7 \%$ ) por tener hijo menor a cargo de dieciséis (16) años de edad o menor de dieciocho (18) años siempre que se encuentre estudiando o por tener hijo inválido de cualquier edad. Veinticuatro (24) años más tarde, el Consejo Nacional de Seguros Sociales Obligatorios a través del Acuerdo $\mathrm{N}^{\circ} 049$ de $1^{\circ}$ de Febrero de 1990, creó un nuevo Reglamento General del Seguro Social Obligatorio de Invalidez, Vejez y Muerte. Este nuevo Acuerdo también fue aprobado por parte del Gobierno Nacional, en esta oportunidad a través del Decreto $\mathrm{N}^{\circ} 758$ del 11 de Abril de 1990 y en su artículo 21 conservó para los pensionados de dicho régimen los incrementos ya referenciados, siempre que se cumplieran los requisitos establecidos en el Acuerdo
$\mathrm{N}^{\circ} 224$ de 1966, extendiendo tal beneficio también para aquellos jubilados (as) que convivieran con compañeros y/o compañeras permanentes. Como adición el Acuerdo $\mathrm{N}^{\circ} 049$ de 1990 fijó en su artículo 22 una disposición referente a la naturaleza de dichos incrementos pensionales, en el entendido de que los mismos no forman parte integrante de las pensiones por invalidez y de vejez.

A la entrada en vigencia del nuevo sistema pensional creado a través de la Ley 100 de 1993, dicha norma no efectuó mención expresa acerca de la vigencia de los incrementos referidos, razón por la cual el Instituto de Seguros Sociales a través de diversos Actos Administrativos comenzó a desconocer tal prestación bajo el argumento de que los mismos habían sido derogados y desaparecidos del actual ordenamiento jurídico. En razón a la situación planteada, las Honorables Corte Suprema de Justicia y Corte Constitucional empezaron a crear una Jurisprudencia tendiente a pronunciarse acerca de la vigencia de los mismos en el sistema jurídico colombiano y sobre la prescriptibilidad o no de los mismos. Es precisamente acerca de los pronunciamientos jurisprudenciales efectuados $\mathrm{y}$ encontrados por parte de ambas Cortes referente al tema, en el que consiste la elaboración del presente artículo científico.

\section{ORIGEN Y NATURALEZA DE LOS INCREMENTOS PENSIONALES.}

Los incrementos pensionales por personas a cargo vinieron a integrar el Ordenamiento jurídico Colombiano con la expedición del Decreto $N^{\circ} 3041$ 
de 19 de Diciembre de 1966, a través del cual fue aprobado el Acuerdo $\mathrm{N}^{\circ} 224$ del mismo año proferido por el Consejo Directivo del Instituto Colombiano de Seguros Sociales, Acuerdo mediante el cual se expidió el Reglamento General del Seguro de Invalidez, Vejez y Muerte de la referida Corporación.

En el artículo 16 del enunciado Decreto se contempló el derecho a incrementar las mesadas pensionales por Invalidez y Vejez en un porcentaje equivalente al $14 \%$ sobre la pensión mínima, para aquellos pensionados que tuviesen a su cargo y bajo su dependencia económica a sus cónyuges. De igual manera se creó un incremento equivalente al 7\% sobre la pensión mínima para aquellos pensionados que tuviesen a su cargo y bajo dependencia económica a hijos inválidos de cualquier edad, hijos menores de 16 años, o menores de 18 siempre que se encontraren estudiando.

Con el transcurrir de los años y la evolución normativa en el tiempo, Los incrementos pensionales por personas a cargo fueron insertados en nuestro Ordenamiento Jurídico en el Acuerdo Nº 049 de 1990 Aprobado por el Gobierno Nacional a través del Decreto $\mathrm{N}^{\circ} 758$ del mismo año. La norma más reciente ya reconoce esta prestación a aquellos pensionados que convivan en unión libre y tengan a su cargo compañero o compañera permanente. Los artículos en los que el referido decreto enuncia los incrementos pensionales son los $\mathrm{N}^{\circ} 21$ y 22. El primero de ellos hace referencia al monto de los porcentajes a los que se puede acceder por concepto de dichos incrementos, la norma en mención plasma lo siguiente:

ARTÍCULO 21. INCREMENTOS DE LAS PENSIONES DE INVALIDEZ POR RIESGO
COMUN Y VEJEZ. Las pensiones mensuales de invalidez y de vejez se incrementarán así:

a) En un siete por ciento (7\%) sobre la pensión mínima legal, por cada uno de los hijos o hijas menores de 16 años o de dieciocho (18) años si son estudiantes o por cada uno de los hijos inválidos no pensionados de cualquier edad, siempre que dependan económicamente del beneficiario $y$,

b) En un catorce por ciento (14\%) sobre la pensión mínima legal, por el cónyuge o compañero o compañera del beneficiario que dependa económicamente de éste y no disfrute de una pensión",

Por su parte la norma referenciada establece en su artículo $\mathrm{N}^{\circ} 22$ la naturaleza de los incrementos Pensionales en los siguientes términos: "Los incrementos de que trata el artículo anterior no forman parte integrante de la pensión de invalidez o de vejez que reconoce el Instituto de Seguros Sociales y el derecho a ellos subsiste mientras perduren las causas que les dieron origen ${ }^{2}$.

\section{LOS INCREMENTOS PENSIONALES POR PERSONAS A ACARGO NO FUERON DEROGADOS POR LA LEY 100 DE 1993. DESARROLLO JURISPRUDENCIAL.}

La Honorable Corte Suprema de Justicia - Sala de Casación Laboral a través de su jurisprudencia se ha encargado de aclarar que con la entrada en vigencia de la Ley 100 de 1993, por medio de la cual se creó el

\footnotetext{
${ }^{1}$ República de Colombia. Ministerio de Trabajo y Seguridad Social. Decreto $N^{\circ} 758$ de 1990, a través del cual se aprobó el Acuerdo $N^{\circ} 049$ de 1990. Diario Oficial No 39303 de 18 de Abril de 1990. Bogotá D.C.

${ }^{2}$ República de Colombia. Ministerio de Trabajo y Seguridad Social. Decreto $N^{\circ} 758$ de 1990, a través del cual se aprobó el Acuerdo $\mathrm{N}^{\circ} 049$ de 1990. Diario Oficial $\mathrm{N}^{\circ} 39303$ de 18 de Abril de 1990. Bogotá D.C.
} 
Sistema de Seguridad Social Integral, los incrementos pensionales por personas a cargo, no perdieron su vigencia, es así, como en SENTENCIA con Radicado $\mathrm{N}^{\circ} 21517$ de 27 de Julio de 2005 se pronunció al respecto en la siguiente forma:

\section{"TERCER CARGO.}

En el acervo demostrativo del cargo el impugnante sostiene que el Tribunal cometió el error de considerar que los incrementos de pensiones contenidos en el Art. 21 del acuerdo 049 de 1990 continúan vigentes, pues habían perdido su efectividad jurídica al crearse el Sistema General de Pensiones por la Ley 100 de 1993. Agrega, además, que tal aseveración la reafirma con lo que expresa el inciso primero del Art. 31 de la tan mentada ley, pues en esta norma se definen las prestaciones que pueden derivarse de la vejez, invalidez o muerte, sin que se hayan mencionado los incrementos objeto de este acápite.

Asegura el casacionista que el Art. 31 de la ley general de pensiones llenó los vacíos de la misma, pero que no por ello se pueda sostener que tales incrementos hayan quedado vigentes; bastaría con leer dicha norma para observar que dentro de su texto no se señalan los susodichos incrementos entre tantas prestaciones taxativamente definidas.

Agrega en sus fundamentos que no por dejarse de mencionar los incrementos de las pensiones en los Arts. 34 y 40 de la Ley 100, quiera ello decir que mantienen su vigencia. Todo lo contrario, reafirma; el no mencionarlos demuestra "que desaparecieron". Insiste también en que esos incrementos "configuran una prestación ajena a las que contempla la aludida Ley". Concluye que tales acrecencias son incompatibles con el nuevo régimen pensional ${ }^{, 3}$.

Los argumentos percibidos en las líneas atrás fueron los utilizados por parte del Apoderado de la entidad Instituto de Seguros Sociales ante la Honorable Corte

\footnotetext{
${ }^{3}$ República de Colombia. Jurisdicción Ordinaria. Corte Suprema de Justicia - Sala de Casación Laboral. Sentencia Radicación N ${ }^{\circ}$ 21517. Magistrados Ponentes: Isaura Vargas Díaz y Jaime Moreno García. Bogotá D.C. Julio 27 de 2005.
}

Suprema de Justicia - Sala de Casación Laboral en el proceso de la referencia con los que se buscó en su momento no dar apertura a una ola de procesos judiciales en los que las pretensiones fuesen el reconocimiento y pago de los incrementos pensionales propios del régimen de prima media con prestación definida. Sin embargo, la Corporación fue enfática en dicha oportunidad para expresar la vigencia de los incrementos pensionales de $14 \%$ y $7 \%$ según fuere el caso basándose en el siguiente argumento:

"El recurrente buscó convencer a esta corporación que el artículo 21 del acuerdo 049 de 1990 desapareció, en razón a que fue omitida su mención dentro de las normas derogadas. Para resolver la dubitativa interpretación, acudiremos al Art. 21 del Código Sustantivo del Trabajo que consagra los principios de favorabilidad y de inescindibilidad de las normas. Esto nos conduce a que en caso de conflicto o duda sobre la aplicación de una norma, prevalece la más favorable al trabajador y que la que se adopte debe aplicarse en su integridad".4.

De igual manera el Órgano jurisdiccional de cierre planteó en la referida Providencia "Es verdad que los incrementos de las pensiones no están involucrados en la mencionada Ley 100, pero ello no significa que pierdan su vigencia; por el contrario, si tal normatividad no los reguló, no quiere decir que los hubiera derogado, entones en ese orden conservan su pleno vigor" 5 .

La Corte Suprema de Justicia fijó el siguiente argumento con el fin de despejar cualquier duda

\footnotetext{
${ }^{4}$ República de Colombia. Jurisdicción Ordinaria. Corte Suprema de Justicia - Sala de Casación Laboral. Sentencia Radicación $N^{\circ} 21517$. Magistrados Ponentes: Isaura Vargas Díaz y Jaime Moreno García. Bogotá D.C. Julio 27 de 2005.

${ }^{5}$ República de Colombia. Jurisdicción Ordinaria. Corte Suprema de Justicia - Sala de Casación Laboral. Sentencia Radicación N ${ }^{\circ}$ 21517. Magistrados Ponentes: Isaura Vargas Díaz y Jaime Moreno García. Bogotá D.C. Julio 27 de 2005.
} 
referente a la vigencia de los incrementos por personas a cargo en el nuevo sistema pensional, "Finalmente, el recurrente aduce una indebida aplicación del Art. 289 de la Ley 100 de 1993, pues dicha norma según su entender derogó todas las disposiciones que le fueran contrarias. Sin embargo, los incrementos a las pensiones para los beneficiarios del régimen del acuerdo I.S.S. 049 de 1990, ya por derecho propio o por el de transición no pueden ser contrarias, por reconocimiento expreso de la misma norma al decir que esta "salvaguarda los derechos adquiridos"(subrayas y negrillas de la ponencia)"6.

Dos años posterior a la expedición de la sentencia acabada de analizar, la Honorable Corte Suprema de Justicia - Sala de Casación Laboral se volvió a pronunciar al respecto de la vigencia de los incrementos pensionales a través de la Sentencia con radicado $\mathrm{N}^{\circ} 29531$ de 5 de Diciembre de 2007 M.P. LUIS JAVIER OSORIO LOPEZ, en esta oportunidad emitiendo un pronunciamiento adicional en el entendido de que al afiliado para poder acceder a ellos, no le resultaba requisito indispensable haber causado su derecho a la pensión de vejez e invalidez en vigencia del Acuerdo $\mathrm{N}^{\circ} 049$ de 1990 aprobado por Decreto $\mathrm{N}^{\circ} 758$ del mismo año. La Corporación estableció:

"Lo expuesto trae consigo para el Caso en particular, que el derecho a los incrementos por personas a cargo y concretamente el equivalente al $14 \%$ sobre la pensión mínima legal por su cónyuge, ingresaron al patrimonio del demandante, a quien se le definió su prestación por vejez con base a la normatividad anterior al ser beneficiario del régimen de transición, y por tanto aunque éste

\footnotetext{
${ }^{6}$ República de Colombia. Jurisdicción Ordinaria. Corte Suprema de Justicia - Sala de Casación Laboral. Sentencia Radicación $\mathrm{N}^{\circ}$ 21517. Magistrados Ponentes: Isaura Vargas Díaz y Jaime Moreno García. Bogotá D.C. Julio 27 de 2005.
}

hubiere completado requisitos para acceder a la pensión en vigencia de la nueva ley de seguridad social, el 21 de enero de 2003, no es dable desconocer tal prerrogativa prevista en el citado Acuerdo del ISS 049 de 1990, cuando frente a dichos incrementos según se explicó no operó la supresión o derogatoria expresa o tácito de la ley (artículos 71 y 72 del Código Civil), por virtud a que sus efectos en verdad jurídicamente no fueron abolidos, conservándose así su aplicación inobjetable en los términos del aludido artículo 31 de la Ley 100 de 1993, lo que de igual manera encuentra respaldo en la protección a la seguridad social que pregonan los artículos 48 y 53 de la Constitución Politica",7.

\section{ANALISIS JURISPRUDENCIAL REFERENTE A LA PRESCRIPCIÓN DE LOS INCREMENTOS PENSIONALES Y EXTINCIÓN DE DICHO DERECHO.}

El Código Civil Colombiano en su artículo 2512 define la prescripción como "un modo de adquirir las cosas ajenas, o de extinguir las acciones o derechos ajenos, por haberse poseído las cosas y no haberse ejercido dichas acciones y derechos durante cierto lapso de tiempo, y concurriendo los demás requisitos legales. Se prescribe una acción o derecho cuando se extingue por la prescripción”»8.

Si bien es cierto, en la actualidad no existe duda en relación a la imprescriptibilidad en el Derecho a las distintas clases de Pensiones que contempla nuestra legislación, no se evidencia tal claridad en lo que respecta a los incrementos pensionales por personas a cargo, es así, como a continuación

\footnotetext{
${ }^{7}$ República de Colombia. Jurisdicción Ordinaria. Corte Suprema de Justicia - Sala de Casación Laboral. Sentencia Radicación $N^{\circ} 29531$. Magistrado Ponente: Luis Javier Osorio López. Bogotá D.C. Diciembre 05 de 2007.

${ }^{8}$ República de Colombia. Congreso. Código Civil. Artículo N ${ }^{\circ}$ 2512.
} 
tendremos la oportunidad de conocer la posición jurisprudencial que existe por parte de la Corte Suprema de Justicia y Corte Constitucional en el sentido de indicar que los mismos están sujetos a prescribir y que por ende dicho derecho podría extinguirse en el evento de no efectuarse las reclamaciones dentro del término legal establecido.

La Honorable Corte Suprema de Justicia Sala de Casación Laboral en Sentencia con radicación $\mathrm{N}^{\circ}$ 27923 de fecha Diciembre 12 de 2007 y en la que figuró como Magistrada Ponente la Dra. Elsy del Pilar Cuello, se pronunció por primera vez acerca de la procedencia del fenómeno jurídico de la prescripción a los incrementos pensionales por personas a cargo.

La Corte Suprema se pronunció en los siguientes términos:

“...pues si precisamente el artículo 22 del Acuerdo 049 de 1990 prevé que los incrementos por persona a cargo "no forman parte integrante de la pensión de invalidez o de vejez que reconoce el Instituto de Seguros Sociales" es lógico que no pueden participar de los atributos y ventajas que el legislador ha señalado para éstas, entre ellas el de la imprescriptibilidad del estado jurídico del pensionado y que se justifican justamente por el carácter fundamental y vital de la prestación, reafirmado por la Constitución de 1991, y además por el hecho de ser de tracto sucesivo, por regla general, $y$ de carácter vitalicio","

En la providencia antes referenciada la Corte Suprema complementó su postura : "La alusión normativa atinente a que el derecho a los incrementos "subsiste mientras perduren las causas que le dieron origen", antes que favorecer la imprescriptibilidad, obran en su contra por cuanto implícitamente parte de

\footnotetext{
${ }^{9}$ República de Colombia. Jurisdicción Ordinaria. Corte Suprema de Justicia - Sala de Casación Laboral. Sentencia Radicación $N^{\circ}$ 27923. Magistrado Ponente: Elsy del Pilar Cuello. Bogotá D.C. Diciembre 12 de 2007.
}

la hipótesis de que se trata de un derecho que no es vitalicio en tanto su persistencia requiere que se sigan dando las causas que le dieron origen, de modo que aunque, parezca redundante, la desaparición de estas provoca su extinción"

Concluye en los siguientes términos: "De ahí que a juicio de esta Sala bien puede aplicarse para efectos de estos incrementos la tesis de que los mismos prescriben si no se reclaman dentro de los 3 años siguientes a su exigibilidad, debiendo entenderse que son exigibles desde el momento en que se produjo el reconocimiento de la pensión de vejez o de invalidez"11.

En el año 2012 la Corte Suprema de Justicia Sala de Casación laboral en su condición de máximo órgano jurisdiccional profirió la Sentencia con Radicación N 40919 de fecha Septiembre 18 M.P. CARLOS ERNESTO MOLINA MONSALVE, en la que hizo referencia al fenómeno jurídico de la prescripción en los incrementos pensionales por personas a cargo. La corporación estableció en esta oportunidad:

"En efecto, ha señalado la Corporación que la calidad del pensionado es permanente y vitalicia, y es en consecuencia imprescriptible la acción para impetrar su reconocimiento. Pero igualmente ha precisado que, una es esa condición del individuo cuya titularidad del derecho pensional no fenece con el transcurrir del tiempo y otra diferente la constituyen los derechos derivados de ese status, tales como el pago de las mesadas pensionales o, en el caso en estudio, los incrementos reclamados, pues

\footnotetext{
${ }^{10}$ República de Colombia. Jurisdicción Ordinaria. Corte Suprema de Justicia - Sala de Casación Laboral. Sentencia Radicación $N^{\circ}$ 27923. Magistrado Ponente: Elsy del Pilar Cuello. Bogotá D.C. Diciembre 12 de 2007.

${ }^{11}$ República de Colombia. Jurisdicción Ordinaria. Corte Suprema de Justicia - Sala de Casación Laboral. Sentencia Radicación $\mathrm{N}^{\circ}$ 27923. Magistrado Ponente: Elsy del Pilar Cuello. Bogotá D.C. Diciembre 12 de 2007.
} 
estos últimos sí prescriben, en criterio de la Corte, según los términos del artículo 488 del Código Sustantivo del Trabajo y del 151 del Código Procesal del Trabajo y de la Seguridad Social", ${ }^{2}$.

Siguió exponiendo el órgano de cierre

"En este orden de ideas, a la luz de la jurisprudencia antes citada, que no hay razón para variar y que por eso en esta oportunidad se reitera, es entonces razonable afirmar la extinción del derecho a incrementar la pensión en los porcentajes señalados en los artículos 21 y 22 del Acuerdo 049 de 1990 aprobado por el Decreto 0758 de igual año, por personas a cargo, por el acaecimiento de la prescripción. Ello al haberse cumplido el plazo trienal establecido por la ley, al punto que no es posible considerar su existencia para ningún efecto, porque al desaparecer del ámbito jurídico entran al terreno de las obligaciones naturales que, como sabe, no tienen fuerza vinculante"13.

Por su parte la Honorable Corte Constitucional a través de la Sentencia T - 791 de 2013 con Ponencia del Magistrado LUIS GUILLERMO GUERRERO PEREZ, también efectuó pronunciamiento tendiente a considerar la aplicación del fenómeno jurídico de la prescripción a los incrementos pensionales. En esta ocasión, el pronunciamiento en vía de tutela se fundamentó así:

"En esta sentencia la sala de la honorable corte constitucional considera que por vía de tutela no se deben proteger derechos alegados como fundamentales, cuando no existe un precedente jurisprudencial claramente definido referente la imprescriptibilidad de los incrementos pensionales en el régimen de prima media con prestación

\footnotetext{
${ }^{12}$ República de Colombia. Jurisdicción Ordinaria. Corte Suprema de Justicia - Sala de Casación Laboral. Sentencia Radicación No 40919. Magistrado Ponente: Carlos Ernesto Molina Monsalve. Bogotá D.C. Septiembre 18 de 2012.

${ }^{13}$ República de Colombia. Jurisdicción Ordinaria. Corte Suprema de Justicia - Sala de Casación Laboral. Sentencia Radicación N ${ }^{\circ}$ 40919. Magistrado Ponente: Carlos Ernesto Molina Monsalve. Bogotá D.C. Septiembre 18 de 2012.
}

definida" ${ }^{\prime \prime}$. La Sala es clara al considerar que es el Órgano de cierre de la jurisdicción ordinaria laboral el encargado de definir acerca de la prescripción o no de derechos patrimoniales anexos a las pensiones de vejez e invalidez" ${ }^{\prime \prime}$.

De igual forma, la Honorable Corte Constitucional en dicha Sentencia, efectuó referencia a la tesis que desde siempre ha venido sosteniendo la Corte Suprema de Justicia en lo atinente a la prescriptibilidad de la prestación objeto de estudio, la Corporación constitucional estableció:

\begin{abstract}
"Reiterando lo antes dicho, ha considerado el órgano de cierre de la Jurisdicción Ordinaria, que si bien los incrementos nacen del reconocimiento de la prestación, estos no forman parte integrante de la pensión, ni del estado jurídico de la persona pensionada, no sólo porque así lo consignó la ley, "sino porque se trata de una prerrogativa cuyo surgimiento no es automático frente a dicho estado, pues está condicionado al cumplimiento de unos requisitos, que pueden presentarse o no", o simplemente extinguirse en el tiempo; requisitos estos, ajenos a las contingencias de invalidez o vejez. que busca amparar el derecho a la seguridad social, y sobre las cuales es que se garantiza la prestación pensional (imprescriptible) en aras de salvaguardar el mínimo vital y el auto sostenimiento en condiciones dignas de las personas afectadas por la contingencia de que se trate" 16 .
\end{abstract}

En el mes de Febrero del año 2015, la Honorable Corte Suprema de Justicia una vez más planteó la

\footnotetext{
${ }^{14}$ República de Colombia. Jurisdicción Constitucional. Corte Constitucional. Sentencia T - 791 de 2013. Magistrado Ponente: Luis Guillermo Guerrero Pérez. Bogotá D.C. Noviembre 12 de 2013.

${ }^{15}$ República de Colombia. Jurisdicción Constitucional. Corte Constitucional. Sentencia T - 791 de 2013. Magistrado Ponente: Luis Guillermo Guerrero Pérez. Bogotá D.C. Noviembre 12 de 2013.

${ }^{16}$ República de Colombia. Jurisdicción Constitucional. Corte Constitucional. Sentencia T - 791 de 2013. Magistrado Ponente: Luis Guillermo Guerrero Pérez. Bogotá D.C. Noviembre 12 de 2013.
} 
sólida tesis referente a la prescripción de los incrementos pensionales por personas a cargo, pronunciándose en los siguientes términos:

"Dado que el cargo viene dirigido por la vía jurídica, se parte de estimar incontrovertible que la esposa del actor siempre dependió económicamente de quien fuera pensionado por invalidez mediante Resolución 2918 de 10 de septiembre de 1991 del ISS y que formuló petición el 4 de marzo de 2008. En ese orden, es incuestionable que entre estas dos fechas transcurrió un tiempo superior a los 3 años de que tratan los artículos 151 del Código Procesal del Trabajo y 488 del procesal de la misma especialidad, por manera que el derecho a los incrementos por personas a cargo se encontraba prescrito, como con reiteración y uniformidad lo ha decantado esta Sala de la Carta,"17.

Después de referirse breve y concisamente a algunas sentencias proferidas por la misma Corporación Jurisdiccional, se concluye en la providencia citada lo siguiente:

"En este orden de ideas, a la luz de la jurisprudencia citada, es razonable afirmar la extinción del derecho a incrementar la pensión en los porcentajes señalados en los artículos 21 y 22 del Acuerdo 049 de 1990, por personas a cargo, por el acaecimiento de la prescripción, al haberse cumplido el plazo trienal establecido por la ley".

Un mes más tarde en relación a la Sentencia estudiada inmediatamente atrás, la Honorable Corte Constitucional tuvo la oportunidad de pronunciarse nuevamente en torno a la procedencia o no del reconocimiento de incrementos pensionales por personas a cargo por vía de Tutela, solicitados a la Administradora de Pensiones en un término superior a los tres años desde el momento del reconocimiento de la prestación. En esta oportunidad la Corporación reiteró que mientras no exista una uniformidad en cuanto a los pronunciamientos de las distintas Salas de la Institución, no se puede desconocer la seria y fundamentada Tesis jurisprudencial que ha venido planteando la Honorable Corte Suprema de Justicia en cuanto a la Prescripción de los incrementos pensionales por personas a cargo. En esta ocasión el máximo órgano de la Jurisdicción constitucional estudió en sede de revisión un fallo de tutela proferido por el Juzgado Quinto Laboral del Circuito de Barranquilla en el que figuró como accionado el Juzgado Cuarto Municipal de Pequeñas Causas Laborales de la misma ciudad por el hecho de haber declarado probada la excepción de Prescripción en un proceso ordinario en el que se pretendía el reconocimiento y pago de un incremento del $14 \%$ por cónyuge a cargo. Las líneas trazadas por la Honorable Corte se leen de la siguiente manera en Sentencia T123 de 2015:

"En suma, como ya quedó visto, no existen pronunciamientos constitucionales reiterados $n i$ posturas uniformes dentro de esta Corte en torno al incremento pensional del 14\%, motivo por el cual, no podría considerarse que una providencia judicial desconoce el precedente constitucional cuando, de conformidad con la jurisprudencia reiterada por la Corte Suprema de Justicia, decide que el incremento del $14 \%$ por personas a cargo está sujeto a prescripción.

En otras palabras, esta Sala de Revisión considera que no es posible concluir que una autoridad judicial que actuó en desarrollo de los principios de independencia y autonomía propios de la actividad jurisdiccional, hubiere incurrido en un desconocimiento del precedente constitucional, al tomar una decisión debidamente sustentada en una hermenéutica del derecho positivo, pero contraria a una interpretación de algunas salas de esta Corporación, la cual no ha sido unánime, más aún cuando la providencia judicial cuestionada sigue el

${ }^{17}$ República de Colombia. Jurisdicción Ordinaria. Corte Suprema de Justicia - Sala de Casación Laboral. Sentencia Radicación $N^{\circ}$ 45197. Magistrado Ponente: Elsy del Pilar Cuello Calderón. Bogotá D.C. Febrero 18 de 2015. 
precedente reiterado en la jurisdicción ordinaria por el juez natural",18.

Conforme a las cinco (5) sentencias estudiadas hasta este punto, se puede deducir que existe una posición muy fuerte por parte de las Altas Cortes jurisdiccionales de nuestro país, en especial de la Corte Suprema de Justicia, encaminadas a clarificar la procedencia de la prescripción en los incrementos pensionales por personas a cargo.

\section{ANALISIS JURISPRUDENCIAL}

\section{REFERENTE A LA IMPRESCRIPTIBILIDAD \\ DE LOS INCREMENTOS PENSIONALES EN EL RÉGIMEN DE PRIMA MEDIA CON PRESTACIÓN DEFINIDA.}

A diferencia de la tesis mayoritaria y dominante que ha sentado la Corte Suprema de Justicia - Sala de Casación Laboral, la Honorable Corte Constitucional se ha inclinado un poco más por la imprescriptibilidad del Derecho a los incrementos pensionales. Lo anterior en sustento de las jurisprudencias que a continuación estudiaremos.

En Sentencia T - 217 de 2013, que tuvo como M.P. al Dr. ALEXEI JULIO ESTRADA, La Honorable Corte Constitucional tuvo la oportunidad de estudiar en Sala Octava de revisión, Acciones de tutelas presentadas en contra del Tribunal Superior del Distrito Judicial de Barranquilla - Sala Laboral en razón a decisiones judiciales proferidas por dicha Institución confirmatorias de fallos de primera instancia de los Juzgados Cuarto y Octavo Laboral

\footnotetext{
${ }^{18}$ República de Colombia. Jurisdicción Constitucional. Corte Constitucional. Sentencia T - 123 de 2015. Magistrado Ponente: Luis Guillermo Guerrero Pérez. Bogotá D.C. Marzo 26 de 2015.
}

del Circuito de Barranquilla consistentes en desconocer el Derecho a incrementos pensionales por personas a cargo bajo el argumento de haber operado el fenómeno jurídico de la Prescripción.

El máximo órgano de la jurisdicción constitucional planteó en la Providencia inmediatamente atrás referenciada, lo siguiente:

\begin{abstract}
"En esta oportunidad la Sala conoce los casos de dos personas que solicitan el incremento pensional del 14\% con base en el artículo 21 del Acuerdo 49 de 1990 aprobado por el Decreto 0758 del mismo año. En los casos acumulados, el incremento del 14\% sobre la mesada pensional ha sido negado porque, a juicio de las autoridades judiciales, en los casos objeto de revisión se configura el fenómeno de prescripción, razón por la cual se declaró probada dicha excepción" $" 19$.
\end{abstract}

Continuó complementando la Honorable Corte Constitucional:

"Por lo anterior, corresponde a la Sala de Revisión determinar si las providencias objeto de análisis constitucional, en los casos planteados, incurrieron en una causal específica de procedibilidad por defecto sustantivo en la modalidad de desconocimiento del precedente judicial sentado por esta Corporación, al sostener que el reclamo de los incrementos del $14 \%$ sobre la pensión mínima legal, de que trata el inciso tercero del artículo 21 del Acuerdo 49 de 1990, que inciden en la cuantificación del derecho a la pensión, son objeto de prescripción, y consecuentemente, en la vulneración de los derechos fundamentales de los actores a la igualdad, al debido proceso, al mínimo vital y móvil y a la seguridad social en pensiones"

\footnotetext{
${ }^{19}$ República de Colombia. Jurisdicción Constitucional. Corte Constitucional. Sentencia T - 217 de 2013. Magistrado Ponente: Alexei Julio Estrada. Bogotá D.C. Abril 17 de 2013.

${ }^{20}$ República de Colombia. Jurisdicción Constitucional. Corte Constitucional. Sentencia T - 217 de 2013. Magistrado Ponente: Alexei Julio Estrada. Bogotá D.C. Abril 17 de 2013.
} 
Una vez planteado el problema jurídico en el caso concreto, la Corporación por unanimidad consideró:

"En el caso en cuestión, la Sala observa que las sentencias recurridas incurren un defecto sustantivo por desconocimiento del precedente jurisprudencial establecido está por la Corte Constitucional, el cual estipula que el término de prescripción es predicable únicamente de las mesadas pensionales no reclamadas y deducido del contenido de las prestaciones, razón por la cual estima la Sala que en los casos analizados, dar aplicación a los artículos 488 del Código Sustantivo del Trabajo y 151 del Código Procesal del Trabajo y de la Seguridad Social, constituye una decisión que vulnera directamente los principios de eficiencia, universalidad y solidaridad con sujeción a los cuales el Estado tiene la obligación de prestar el servicio público de la seguridad social ${ }^{21}$. Por ello, esta Sala declarará que, los derechos fundamentales al debido proceso, acceso a la administración de justicia y seguridad social de los ciudadanos Salgado Herrera Eduardo Enrique y Constante Gutiérrez Alfredo fueron vulnerados".

Concluyó la Corporación Constitucional:

"Lo anterior en atención al principio de la imprescriptibilidad de los derechos a la seguridad social, por cuanto el derecho a la pensión o los incrementos que por ley se desprendan de éste son imprescriptibles, en esa medida la prescripción solo es aplicable a las mesadas no reclamadas con anterioridad a los 3 años de solicitadas, por lo tanto de acoger la tesis que al reajuste a la pensión de vejez del $14 \%$, en relación con el cónyuge o compañero o compañera permanente del beneficiario de dicha pensión, que dependiese económicamente de éste y que no esté disfrutando de una pensión, de conformidad con lo dispuesto en el artículo 21 del Acuerdo 49 de 1990, se le puede aplicar prescripción, equivale a perder una fracción de recursos de este derecho o parte del mismo. Por consiguiente la interpretación hecha por la Sala laboral del Tribunal Superior de Barranquilla al decidir aplicar la norma citada, dio a los accionantes un trato diferente $e$ injustificado frente a otras personas en igualdad de circunstancias, incurriendo con sus decisiones en un trato discriminatorio, con la consecuente vulneración del derecho fundamental a la igualdad de los peticionarios, al

\footnotetext{
${ }^{21}$ República de Colombia. Jurisdicción Constitucional. Corte Constitucional. Sentencia T - 217 de 2013. Magistrado Ponente: Alexei Julio Estrada. Bogotá D.C. Abril 17 de 2013.
}

contrariar lo estipulado en el artículo 48 de la Constitución Politica",22.

En el año 2014 la Honorable Corte Constitucional en Sentencia T- 831 - 2014 con Ponencia del Magistrado JORGE IGNACIO PRETELT CHALJUB, se pronunció nuevamente acerca de la imprescriptibilidad del Derecho a los incrementos pensionales por personas a cargo equivalentes al catorce y siete por ciento (14\% - 7\%). En esta oportunidad el cuerpo colegiado indicó: "Los incrementos pensionales referidos constituyen una prerrogativa, aplicada a la pensión mínima legal, a la cual se accede cuando el cónyuge o compañero(a) permanente del beneficiario depende de este y no disfruta de pensión alguna, o cuando se trata de un hijo en situación de discapacidad que depende económicamente del beneficiario de la pensión. Adicionalmente, el derecho a tales incrementos subsiste mientras perduren las causas que les dieron origen, con lo cual se entiende que el mismo puede ser reclamado en la medida en que persistan las condiciones que a él dieron lugar, por lo cual tal prerrogativa no se vería afectada por el fenómeno de la prescripción",23.

El más reciente pronunciamiento acerca de la imprescriptibilidad de los incrementos pensionales por personas a cargo, lo efectuó la Honorable Corte Constitucional a través de la Sentencia T - 369-2015, en la que figuró como Magistrado Ponente el Dr. JORGE IGNACIO PRETELT CHALJUB. En dicha

\footnotetext{
${ }^{22}$ República de Colombia. Jurisdicción Constitucional. Corte Constitucional. Sentencia T - 217 de 2013. Magistrado Ponente: Alexei Julio Estrada. Bogotá D.C. Abril 17 de 2013.

${ }^{23}$ República de Colombia. Jurisdicción Constitucional. Corte Constitucional. Sentencia T - 831 de 2014. Magistrado Ponente: Jorge Ignacio Pretelt Chaljub. Bogotá D.C. Noviembre 11 de 2014.
} 
providencia el cuerpo colegiado ratifica su posición ya conocida y hace referencia a las dos sentencias que hemos estudiado con anterioridad y que aluden la tesis de imprescriptibilidad de los incrementos pensionales. En esta ocasión la Autoridad Judicial Constitucional estableció:

"Esta Sala considera que, existiendo dos posibles interpretaciones del artículo 22 del Acuerdo 049 de 1990, la que mejor realiza los derechos fundamentales del actor es aquella aplicada en la Sentencia T- 217 de 2013 y posteriormente reiterada en la Sentencia $T-831$ de 2014, que resulta más favorable al peticionario, por cuanto en esas oportunidades la Corte consideró que el derecho en mención no se encuentra sometido a la regla de prescripción de las acreencias laborales de tres (3) años. En efecto, en ninguna de las normas citadas, que regulan el incremento bajo estudio, se establece que dicha regla deba ser aplicada al incremento en mención, pues al definirse la naturaleza del mismo, sólo se señala que el incremento del $14 \%$ sobre la mesada mínima por cónyuge a cargo subsiste mientras perduren las causas que le dieron origen. De tal forma, lo considerado en dichos fallos respecto de la imprescriptibilidad del derecho en comento se encuentra en consonancia con el principio de favorabilidad, razón por la cual concluir que tal derecho se encuentra afectado por el fenómeno de la prescripción, en perjuicio de los peticionarios, contraría dicho principio, e implica una violación directa de la Constitución ",24.

\section{CONCLUSIONES}

Una vez culminado el estudio normativo y jurisprudencial en relación a los incrementos pensionales creados por el Acuerdo № 049 de 1990 aprobado por Decreto $\mathrm{N}^{\circ} 758$ del mismo año, se puede deducir sin vacilación alguna que los mismos se encuentran vigentes hoy día después de más de 25 años de haber entrado en rigor la norma que los creó. Es claro, que dichas dudas referentes a la vigencia de los mismos con la entrada en vigencia del nuevo Sistema de Seguridad Social (Ley 100 de 1993), las aclaró la Jurisprudencia proferida por Dos (2) instituciones jurisdiccionales como la Corte Suprema de Justicia - Sala de Casación Laboral y Corte Constitucional - Salas de revisión. De igual forma queda claro con posterioridad a la transcripción del presente artículo científico que los referidos órganos jurisdiccionales han sentado sendas líneas jurisprudenciales que van en contravía en lo que respecta a la prescripción.

Conforme a lo estudiado, se puede observar que existen dos posiciones con argumentos bien fundamentados referentes a extinción del derecho a los incrementos pensionales. Por una parte se puede concluir que el máximo órgano de la jurisdicción ordinaria es enfático en considerar que la prestación referida es susceptible de extinguirse por el fenómeno jurídico de la prescripción. Por otra parte se deduce que el máximo órgano de la jurisdicción constitucional se identifica con la tesis consistente en que el derecho a los incrementos de $14 \%$ y $7 \%$ por personas a cargo, no está sujeto a extinguirse por el fenómeno jurídico de la prescripción. De esta manera se culmina el análisis normativo y jurisprudencial con el cual se busca transmitir al lector ampliar sus conocimientos referentes al sistema de seguridad social, específicamente en el tema de pensiones.

\section{BIBLIOGRAFÍA}

República de Colombia. Congreso. Código Civil.

\footnotetext{
${ }^{24}$ República de Colombia. Jurisdicción Constitucional. Corte
ditucional. Sentencia T - 369 de 2015. Magistrado Ponente:

${ }^{24}$ República de Colombia. Jurisdicción Constitucional. Corte
Constitucional. Sentencia T - 369 de 2015. Magistrado Ponente: Jorge Ignacio Pretelt Chaljub. Bogotá D.C. Junio 18 de 2015.
} 
República de Colombia. Jurisdicción

Constitucional. Corte Constitucional. Sentencia T 217 de 2013. Magistrado Ponente: Alexei Julio

Estrada. Bogotá D.C. Abril 17 de 2013.

República de Colombia. Jurisdicción

Constitucional. Corte Constitucional. Sentencia T 369 de 2015. Magistrado Ponente: Jorge Ignacio Pretelt Chaljub. Bogotá D.C. Junio 18 de 2015.

República de Colombia. Jurisdicción

Constitucional. Corte Constitucional. Sentencia T 831 de 2014. Magistrado Ponente: Jorge Ignacio Pretelt Chaljub. Bogotá D.C. Noviembre 11 de 2014.

República de Colombia. Jurisdicción Constitucional. Corte Constitucional. Sentencia T 791 de 2013. Magistrado Ponente: Luis Guillermo Guerrero Pérez. Bogotá D.C. Noviembre 12 de 2013.

República de Colombia. Jurisdicción Ordinaria. Corte Suprema de Justicia - Sala de Casación Laboral. Sentencia Radicación $N^{\circ}$ 27923. Magistrado Ponente: Elsy del Pilar Cuello. Bogotá D.C. Diciembre 12 de 2007.

República de Colombia. Jurisdicción Ordinaria. Corte Suprema de Justicia - Sala de Casación Laboral. Sentencia Radicación N 29531. Magistrado Ponente: Luis Javier Osorio López. Bogotá D.C. Diciembre 05 de 2007.

República de Colombia. Jurisdicción Ordinaria. Corte Suprema de Justicia - Sala de Casación Laboral. Sentencia Radicación $\mathrm{N}^{\circ} 21517$. Magistrados Ponentes: Isaura Vargas Díaz y Jaime Moreno García. Bogotá D.C. Julio 27 de 2005.

República de Colombia. Ministerio de Trabajo y Seguridad Social. Decreto $N^{\circ} 758$ de 1990, a través del cual se aprobó el Acuerdo N$^{\circ} 049$ de 1990. Diario Oficial N 39303 de 18 de Abril de 1990. Bogotá D.C 